Vahid Bay 1, 2, Irvan Masoudi Asl ${ }^{2}$, Alireza Mahdavi Hezaveh ${ }^{3}$, Mahboobeh Asadzadeh ${ }^{2}$, Alireza Heidari ${ }^{1}$, Elaheh Yazarloo ${ }^{1}$

${ }^{1}$ Health Management and Social Development Research Center, Golestan University of Medical Sciences, Gorgan, Iran

${ }^{2}$ Department of Healthcare Services Management, School of Health Management \& Information Sciences, Iran University of Medical Sciences,

Tehran, Iran

${ }^{3}$ Center for Noncommunicable Disease Control \& Prevention and Head of CVD Control \& Prevention Office, Tehran, Iran

\title{
Factors associated with control of type 2 diabetes mellitus in North Iran
}

\section{ABSTRACT}

Backround. Diabetes is an important public health problem, one of four priority noncommunicable diseases targeted for action by world leaders. The aim of this study was to investigate the factors affecting diabetes control in patients with type 2 diabetes in the rural areas of northern Iran.

Methods. This study was conducted following a descriptive-analytical cross-sectional study design based on the data of 308 patients with type 2 diabetes in the rural areas of Golestan province. The samples were selected through two-stage stratified random sampling. Data were collected using a questionnaire (completed by the interviewer) and by measuring the blood glucose, blood pressure, and lipid profile of patients and also using data from patients' records. Data were analyzed using descriptive and analytical statistics and SPSS version 19.

Results. The mean age of patients was $57 \pm 15$ years and 220 patients $(\mathbf{7 1} \%)$ were female. Fifty-five percent of patients had a family history of diabetes and $69 \%$ had comorbidity. The mean vegetable intake in patients was 3 days a week with 1.5 servings per day and only $20 \%$ had exercise at least three times a week. The proportion of patients with adequately controlled glycated

Address for correspondence:

Irvan Masoudi Asl

Department of Healthcare

Services Management

School of Health Management

\& Information Sciences, Iran

University of Medical Sciences, Tehran, Iran

e-mail: aramiyan3@yahoo.com

Clinical Diabetology 2020, 9; 6: 426-432

DOI: 10.5603/DK.2020.0061

Received: 06.10.2020 hemoglobin ( $\mathrm{HBA}_{1 \mathrm{c}}$ ), blood pressure (BP), triglyceride (TG), low-density lipoprotein (LDL), and high-density lipoprotein (HDL) were 27, 91, 31, 41 and 55.5\%, respectively. There was also a significant relationship between the controlled blood glucose with increasing age, absence of comorbidity, the number of nutrition counseling, and lowering blood triglycerides.

Conclusion. The results of this study showed poor blood glucose control in the studied geography. Therefore, considering these data, it seems necessary to review the national plan for the prevention and control of diabetes. (Clin Diabetol 2020; 9; 6: 426-432)

Key words: type 2 diabetes, diabetes control, glycated hemoglobin

\section{Introduction}

Diabetes is a serious, chronic disease that occurs when there are raised levels of glucose in the blood because the body cannot produce any or enough of the hormone insulin or use insulin effectively. Raised blood glucose, a common effect of uncontrolled diabetes, may, over time, lead to serious damage to the heart, blood vessels, eyes, kidneys and nerves [1, 2]. The International Diabetes Federation (IDF) estimated the number of people with diabetes increases to 451 million if the age is expanded to 18-99 years, and according to prediction of the World Health Organization (WHO), diabetes is the seventh cause of mortality at $2030[2,3]$.

The prevalence of diabetes worldwide increased from $4.7 \%$ in 1998 to $8.5 \%$ in 2014 (in people over 18 years), indicating an increasing prevalence of diabetes worldwide. The International Diabetes Federation also 
estimated that the prevalence of diabetes in Iran in 2015 was $8.5 \%$ (in the population of $20-79$ years) and based on the provincial reports, the prevalence of diabetes in the Golestan province was also estimated to be $10 \%$ (in the population over 18 years). While the prevalence of diabetes in the middle- and low-income countries is increasing at a faster rate, and if there is no proper action to tackle the disease, it is estimated that by 2040, there will be approximately 642 million people with diabetes $[2,4]$.

The causes of type 2 diabetes are not completely understood but there is a strong link with overweight and obesity and with increasing age as well as with ethnicity and family history [2]. Some risk factors for type 2 diabetes such as genetics, ethnicity and age - are not modifiable. Others, such as being overweight or obese, unhealthy diet, insufficient physical activity and smoking are modifiable through behavioral and environmental changes [1]. Diabetes is a chronic, progressive disease but people who have diabetes can live long, high quality lives with good diabetes management [2]. According to the report by $\mathrm{WHO}$, diabetes can be treated and its consequences avoided or delayed with diet, physical activity, medication and regular screening and treatment for complications [3]. But unfortunately many studies that investigated the control and care of diabetes in different countries, especially in Iran, mostly indicate that the status of care and control of diabetes is not desirable [5-15].

In an effort to address this growing health challenge, since early this decade world leaders have committed to reducing the burden of diabetes as one of four priority noncommunicable diseases (NCDs). In our country, the National Program for Prevention and Control of Type 2 Diabetes, with the main purpose of prevention and control of diabetes and its complications, has been integrated into the family physician program of rural areas in our country at 2004 and is running. Therefor the aim of this study was to investigate the factors affecting diabetes control in patients with type 2 diabetes in the rural areas of northern Iran.

\section{Methods}

This study was a descriptive-analytical cross-sectional study conducted between April 2018 and April 2019 based on the data of 340 patients with type 2 diabetes who were selected through two-stage stratified random sampling (stratified proportional allotment). The study population consisted of patients with diabetes with medical records in the rural healthcare centers of Golestan province in north Iran. Inclusion criteria included type 2 diabetes, being older than 20 years, at least one year since the initiation of treatment, and willingness to cooperate.
The study consisted of two consecutive stages. In the first stage, after obtaining the consent of the participants, data on the factors affecting diabetes control were collected from the information recorded in the paper and electronic records of the patients as well as using a questionnaire (completed by the interviewer). In the second stage, all participants were evaluated for glycated hemoglobin ( $\left.\mathrm{HBA}_{1 \mathrm{c}}\right)$, blood pressure (BP), and lipid profile in order to determine the status of diabetes control. In the process of patient evaluation performed by trained experts, blood pressure was measured using a mercury sphygmomanometer in the sitting position. The BT1500 autoanalyzer was also used for the measurement of glycated hemoglobin and lipid profile of patients. The data were finally entered into SPSS software and analyzed using descriptive (such as mean, standard deviation, etc.) and analytical (Pearson correlation coefficient, chi-square, and independent t-test) statistics.

\section{Results}

In this study, out of 340 cases studied, 308 patients were included in the final analysis, with a response rate of $91 \%$. Of the participants, $88(28 \%)$ were male and 220 (71\%) were female. The mean age was $57 \pm 15$ years and the youngest and oldest age was 24 and 86 years, respectively. The mean household size in the participants was 4 persons. In terms of education level, the majority of participants (62\%) were illiterate. Most of the participants were housewives (72\%). The majority of the participants were married (82\%). The mean duration of diabetes at the time of diagnosis was 7.8 years. Table 1 shows the frequency distribution of some of the variables studied in patients with type 2 diabetes.

The mean glycated hemoglobin $\left(\mathrm{HBA}_{1 \mathrm{c}}\right)$ was $8.1 \pm 1.7$ and the mean body mass index (BMI) was $29 \pm 6 \mathrm{~kg} / \mathrm{m}^{2}$. The proportion of patients with well controlled $\mathrm{HBA}^{1 \mathrm{C}}(\leq 7)$, blood pressure (BP) $(\leq 140 / 90)$, triglyceride (TG) $(\leq 150)$, low-density lipoprotein $(L D L)(\leq 100)$, and high-density lipoprotein $(H D L)(\geq 50)$ were $27,91,31,41$, and $55.5 \%$, respectively.

According to the results of the independent t-test, the mean age and number of nutrition counseling per month were significantly higher in those who had controlled glycated hemoglobin and the mean blood triglyceride levels were significantly higher in those who had uncontrolled glycated hemoglobin $(P<0.05)$. Table 2 shows the comparison of mean age, blood triglyceride, and the number of nutrition counseling with glycated hemoglobin control status in the subjects.

Chi-square test results also showed that there was a significant relationship between the glycated hemo- 
Table 1. Frequency distribution of some of the variables studied in patients with type 2 diabetes

\begin{tabular}{|c|c|c|c|c|}
\hline Variable & & Number & Percentage & Descriptions \\
\hline \multicolumn{5}{|l|}{ Education } \\
\hline & Illiterate & 192 & 62.3 & \\
\hline & Less than a high school diploma & 106 & 4.4 & \\
\hline & Diploma & 8 & 2.6 & \\
\hline & Academic & 2 & 0.6 & \\
\hline \multicolumn{5}{|l|}{ Marital status } \\
\hline & Married & 255 & 82.7 & \\
\hline & Single & 3 & 1 & \\
\hline & Divorced & 6 & 1.9 & \\
\hline & Widowed & 44 & 14.3 & \\
\hline \multicolumn{5}{|l|}{ Occupation } \\
\hline & Housewife & 222 & 72.1 & \\
\hline & Worker & 15 & 4.9 & \\
\hline & Farmer & 28 & 9.1 & \\
\hline & Employee & 3 & 1 & \\
\hline & Self-employed & 15 & 4.9 & \\
\hline & Retired & 11 & 3.6 & \\
\hline & Unemployed & 14 & 4.5 & \\
\hline \multicolumn{5}{|l|}{ Income } \\
\hline & Less than 1 million Tomans & 217 & 70.4 & \\
\hline & Between 1 and 2 million Tomans & 86 & 27.8 & \\
\hline & More than 2 million Tomans & 5 & 1.6 & \\
\hline \multicolumn{5}{|l|}{ Family history } \\
\hline & Yes & 169 & 55 & \\
\hline & No & 139 & 45 & \\
\hline \multicolumn{5}{|l|}{ Insurance coverage } \\
\hline & Yes & 303 & 98.4 & $68 \%$ had rural insurance \\
\hline & No & 5 & 1.6 & \\
\hline \multicolumn{5}{|l|}{ Type of treatment } \\
\hline & Medication-free treatment (diet, etc.) & 4 & 1 & \\
\hline & Tablet & 253 & 82 & \\
\hline & Insulin & 51 & 17 & \\
\hline \multicolumn{5}{|l|}{ Comorbidity } \\
\hline & Yes & 211 & 68.5 & $30 \%$ had hypertension \\
\hline & No & 97 & 31.5 & \\
\hline \multicolumn{5}{|c|}{ Complications of diabetes } \\
\hline & Yes & 108 & 35 & \\
\hline & No & 200 & 65 & \\
\hline \multicolumn{5}{|l|}{ Attending physician } \\
\hline & General practitioner (GP) & 139 & 45 & \\
\hline & Specialist & 169 & 55 & $\begin{array}{l}\text { They were referred to a specialist } \\
\text { physician at least once a year to } \\
\text { control diabetes }\end{array}$ \\
\hline $\begin{array}{l}\text { Cigarette smoking, } \\
\text { hookah smoking, }\end{array}$ & Patients with cigarette smoking & 3 & 0.9 & $\begin{array}{l}\text { With an average consumption } \\
\text { of } 16.7 \pm 2.9\end{array}$ \\
\hline \multirow[t]{2}{*}{ and drug use } & Patients with hookah smoking & 1 & 0.3 & $\begin{array}{l}\text { With an average consumption } \\
\text { of } 2 \text { times a day }\end{array}$ \\
\hline & Patients with drug use & 25 & 8 & \\
\hline \multirow[t]{2}{*}{ Exercise } & $\begin{array}{l}\text { Exercising at least three times a week } \\
\text { (for } 150 \text { minutes) }\end{array}$ & 61 & 20 & $\begin{array}{l}\text { With a mean of } 4.5 \pm 2 \text { days a week } \\
\text { and } 37 \pm 16 \text { minutes a day }\end{array}$ \\
\hline & $\begin{array}{l}\text { Not exercising at least three times } \\
\text { a week (for } 150 \text { minutes) }\end{array}$ & 247 & 80 & \\
\hline
\end{tabular}


Table 1 (cont.). Frequency distribution of some of the variables studied in patients with type 2 diabetes

\begin{tabular}{|c|c|c|c|c|}
\hline Variable & & Number & Percentage & Descriptions \\
\hline \multirow{4}{*}{$\begin{array}{l}\text { Fruit and vegetable } \\
\text { intake }\end{array}$} & Vegetable intake & - & - & The mean vegetable intake was \\
\hline & & & & $3 \pm 1.9$ days per week with \\
\hline & & & & $1.5 \pm 0.8$ servings per day \\
\hline & Fruit intake & - & - & $\begin{array}{l}\text { The mean fruit intake was } 4.5 \pm 2 \\
\text { days per week and } 1.8 \pm 1 \text { servings } \\
\text { per day }\end{array}$ \\
\hline \multirow[t]{2}{*}{ Care taken } & $\begin{array}{l}\text { Patients who were visited at least sea- } \\
\text { sonally by a physician form healthcare } \\
\text { centers }\end{array}$ & 109 & 35 & \\
\hline & $\begin{array}{l}\text { Patients who were visited monthly by } \\
\text { a health worker form healthcare centers }\end{array}$ & 62 & 20 & $\begin{array}{l}\text { According to medical records data, } \\
92 \% \text { of patients were seasonally } \\
\text { cared for by health workers }\end{array}$ \\
\hline $\begin{array}{l}\text { Glycated } \\
\text { hemoglobin test }\end{array}$ & $\begin{array}{l}\text { Patients who had undergone at least } 2 \\
\text { tests per year }\end{array}$ & 95 & 31 & \\
\hline
\end{tabular}

Table 2. The comparison of mean age, blood triglyceride, and the number of nutrition counseling with glycated hemoglobin control status in the subjects

\begin{tabular}{|c|c|c|c|}
\hline Variable & $\begin{array}{c}\text { Age } \\
(\text { Mean } \pm \text { SD) }\end{array}$ & $\begin{array}{c}\text { Number of nutrition } \\
\text { counseling (Mean } \pm \text { SD) }\end{array}$ & $\begin{array}{l}\text { Triglyceride }[\mathrm{mL} / \mathrm{dL}] \\
(\text { Mean } \pm \text { SD) }\end{array}$ \\
\hline Controlled $\mathrm{HBA}_{1 \mathrm{c}}(\mathrm{n}=104)$ & $59.81 \pm 10.3$ & $0.85 \pm 1.7$ & $175.40 \pm 86.1$ \\
\hline Uncontrolled $\mathrm{HBA}_{1 \mathrm{c}}(\mathrm{n}=204)$ & $55.60 \pm 9.6$ & $0.43 \pm 1.4$ & $223.52 \pm 141.7$ \\
\hline$P$ value & $P=0.001$ & $P=0.048$ & $P=0.001$ \\
\hline
\end{tabular}

Table 3. The comparison of the frequency distribution of glycated hemoglobin status according to the presence of comorbidity in the subjects

\begin{tabular}{|c|c|c|c|c|}
\hline \multicolumn{2}{|c|}{ Glycated hemoglobin status } & \multirow{2}{*}{$\begin{array}{c}\text { Uncontrolled n (\%) } \\
64(66)\end{array}$} & \multirow{2}{*}{$\begin{array}{c}\text { Controlled n (\%) } \\
33(34)\end{array}$} & \multirow[t]{2}{*}{ Chi-square test results } \\
\hline Comorbidity & No & & & \\
\hline & Hypertension & $52(56.5)$ & $40(43.5)$ & \multirow{3}{*}{$\begin{array}{c}P=0.044 \\
X^{2}=8.1 \\
d f=3\end{array}$} \\
\hline & Dyslipidemia (blood lipid disorder) & $44(78.6)$ & $12(21.4)$ & \\
\hline & Hypertension and dyslipidemia & $42(70)$ & $18(30)$ & \\
\hline
\end{tabular}

globin status and the presence of comorbidity $(P=0.044)$. The comparison of the frequency distribution of glycated hemoglobin status according to the presence of comorbidity in the subjects is shown in Table 3.

\section{Discussion}

In the present study, $71 \%$ of patients were female. In domestic studies, this percentage ranged from 62 to $81 \%[6,16,17]$. In the Middle East, women are more likely to have diabetes than men [2]. It can be said that a sedentary lifestyle in women is one of the causes. Also according to our findings, there was no significant relationship between gender and blood glucose control status, which is in line with the findings of a study conducted in Malaysia [14] and with other findings from domestic studies and Asian and African studies $[6,18,19]$.

In the present study, the control rates of glycated hemoglobin $\left(\mathrm{HBA}_{1 \mathrm{c}}\right)$, blood pressure $(\mathrm{BP})$, low-density lipoprotein (LDL), and triglyceride (TG) in patients covered by the National Diabetes Control Program were 27, 91,41 and $31 \%$, respectively. Control rate of glycated hemoglobin level as one of the most important therapeutic targets of diabetes ranged from 21 to $27 \%$ in the similar domestic studies $[6,7,20]$ and 29.3 to $46 \%$ in the Arabic countries on the periphery of the Persian 
Gulf (Saudi Arabia, United Arab Emirates, and Oman) [21]. This index was reported to be 50,40 , and $88 \%$ in the studies conducted in China, the United States, and Sweden, respectively $[12,22,23]$. It can be said that the level and quality of blood glucose control in the rural areas of Golestan province, like in other studies in the rural areas of our country, is not favorable and is far from the American Diabetes Association's (ADA's) standards of medical care and our national standards.

The International Diabetes Federation (IDF) has also cited ethnicity, genetics, and age as non-modifiable risk factors for type 2 diabetes [5]. Although many of the diabetes-predisposing genes have not yet been identified, it is known that the disease is polygenic and multifactorial. Various genetic loci have been implicated in susceptibility to the disease. Environmental factors (such as nutrition and physical activity) also influence its phenotypic expression [16]. In this study, 55.2\% of patients had a history of diabetes in their first-degree relatives. The data of the present study, like other domestic studies and international resources, indicated the important role of genetic factors in the development of type 2 diabetes $[4,5,17,18]$.

The mean age of the patients was 57.1 (57 years for men and 56 years for women). Also, $75 \%$ of the patients were over 50 years old, which is consistent with the results of the country studies $[6,17,24]$. It is natural that the prevalence of diabetes increases with age. This is because as the person ages, he or she may lose physical activity and gain weight, and this increase in fat deposits around the abdomen and upper body, especially in women after menopause. Low activity and weight gain decrease insulin activity and develop insulin resistance [6]. Also, there was a significant relationship between an increase in the mean age of patients and a more favorable blood glucose control status in our study $(P=0.001)$. Some studies have also cited age as a positive predictor (but not a strong factor) in controlling blood glucose. These data are in line with the findings of studies conducted in Asia and Africa [14, 18, 25, 26].

Various studies have shown that obesity plays a role in the pathogenesis of type 2 diabetes. It is generally accepted that obesity is responsible for disease emergence in those who are genetically susceptible. The World Health Organization (WHO) stated in 1980 that obesity is one of the most important risk factors for type 2 diabetes [1], and the International Diabetes Federation (IDF) also lists obesity as a risk factor for diabetes [2]. Our findings showed that the mean patients' BMI was $29 \mathrm{~kg} / \mathrm{m}^{2}$ and about $78.6 \%$ of patients were in the overweight or obesity range. This is in line with the results of domestic studies, indicating an undesirable prevalence of overweight and obesity among type 2 diabetic patients in the country $[6,16]$. Also, our findings showed a significant relationship between the mean high triglyceride levels and poor blood glucose control in patients $(P=0.001)$. This finding is consistent with the studies conducted in Malaysia, Japan, and Australia that found a significant association between dyslipidemia and poor blood glucose control $[14,26,27]$.

For many people with diabetes, the challenging part of the treatment plan is to determine how to eat and following a diet. Every person with diabetes must actively participate in training, self-management, and treatment planning with their health care team, including in the development of their individual diet plan [28]. In the present study, the mean vegetable intake was 3 days a week with 1.5 servings a day, and the mean fruit intake was 4.5 days a week with the mean intake of 1.8 servings a day. Our study data are consistent with the mean fruit and vegetable intake reported in the domestic studies. However, it is far from the recommendations of the food pyramid which are based on a daily intake of 2-4 fruit units and 5-3 vegetable units [7] and the recommendations of the International Diabetes Federation (IDF) which are based on the daily use of at least three units of fruit and vegetables in individuals [2]. Also, in our study, there was a significant relationship between the mean number of nutrition counseling services provided and blood glucose control $(P=0.048)$, such that patients who had experienced more nutrition counseling had more favorable blood glucose control status.

Proper and regular physical activity reduces insulin resistance in people with diabetes. Therefore, the American Diabetes Association (ADA) has recommended that adults with both type 1 and type 2 diabetes should exercise for at least 150 minutes of moderateto-vigorous-intensity aerobic activity per week (at least 3 days per week, without interruption, more than 2 consecutive days) [28]. In our study, 247 (80.2\%) of the participants did not exercise normally during the week, but 61 (19.8\%) reported a mean exercise of 4.56 \pm 1.8 days per week and $0.37 \pm 0.16$ minutes per day, which indicates an undesirable level of proper physical activity in the rural areas of the province under study.

Comorbidity is common in diabetic patients. These conditions have a significant impact on the treatment and management of type 2 diabetes, such that hypertension has also been reported in a significant proportion of adults with diabetes, and patients with hypertension alone have often shown evidence of insulin resistance $[29,30]$. Our study showed that there was a significant relationship between having comorbidity (hypertension, dyslipidemia) and glycated hemoglobin 
levels, such that those with controlled diabetes had less comorbidity than those with uncontrolled one (based on the chi-square test, $P=0.044)$. These findings are in line with studies conducted in Asia and Australia $[14,18,26,27]$.

In our study, no significant relationship was found between other variables including income level, occupation, education level, marital status, etc. and blood glucose control status. These findings are consistent with some of the findings from domestic and Arabic studies, respectively indicating that there was no significant relationship between (cigarette) smoking and occupation with blood glucose control levels [6, 25], but are inconsistent with other studies in Japan and Ethiopia, which respectively indicated a significant relationship between (cigarette) smoking and occupation with blood glucose control levels [19, 26]. The reason for this lack of correlation between some variables and glucose control levels can be attributed to the homogeneity of some variables in the rural statistical population followed by the homogeneity of variables among the patients under study, such that, in our study, $83 \%$ of participants were married, $97 \%$ had education level less than a high school diploma, $98 \%$ had an income of less than 2 million Tomans, $72 \%$ of women were housewives, and $2 \%$ were cigarette and hookah smoker. Such homogeneity among participants may affect the above-mentioned variables.

\section{Limitations of the study}

This study faced some difficulties and limitations that attempted to be adjusted by the following strategies. The first limitation was the lack of proper cooperation of patients during the study stages due to the parallelization of the project implementation time with the agricultural season in the rural areas of the province. It was attempted to attract cooperation by providing patients with proper justification for the importance of the plan and properly encouraging them to participate in the plan as well as by using flexible scheduling to invite patients. The second limitation was the illegibility of some medical records. The solution adopted for this limitation was to obtain consultative and technical advice from the medical staff of the study center and to randomly replace the illegible medical records with the new ones.

\section{Conclusion}

The findings of our study showed the frequency and relevance of some of the factors affecting blood glucose control as well as poor blood glucose control status in patients with type 2 diabetes in rural areas (patients were treated under the supervision of government healthcare centers).

\section{Acknowledgments}

Hereby, the authors of this research plan find it necessary to express their gratitude to the Vice-Chancellor for Health Affairs of Golestan University of Medical Sciences and the staff and managers of health networks in the cities of this province for their cooperation in this research.

\section{Ethical considerations}

This research has a code of ethics No. 1396.276 and date of approval: 18.2.2018. All participants were given the necessary information regarding the purposes of the project and the confidentiality of the information. The participants voluntarily participated in the project after completing the informed consent form.

\section{Conflict of interest}

The authors report no conflicts of interest in this study.

\section{REFERENCES}

1. World Health Organization. Global report on diabetes. 2016. https://www.who.int/publications-detail-redirect/9789241565257.

2. IDF DIABETES ATLAS Eighth edition 2017. International Diabetes Federation 2017

3. World Health Organization. Facts Sheets. http://who.int/mediacentre/factsheets/fs312/en/.

4. Ministry of Health and Medical Education. Golestan University of Medical Sciences. prevalence of diabet in golestan province. 2017 May 29

5. Fallah S, Rostamzadeh S. Success of the family practice plan in diabetes control. Journal of Health. 2016; 7(4): 417-24.

6. Khazaei S, Saatchi A, Mirmoeini R, et al. Assessing treatment and care in patients with type 2 diabetes in rural regions of Hamadan Province in 2013. Scientific Journal of Hamadan University of Medical Sciences. 2015; 21(4): 318

7. Delpisheh A, Azizi H, Dantalab Es, et al. Quality of care and blood sugar control in type II diabetic patients of rural areas under the care by family physicians. Iranian Journal of Diabetes and Metabolism. 2016; 14(3): 189-198.

8. Al-Kaabi J, Al-Maskari F, Saadi H, et al. Physical activity and reported barriers to activity among type 2 diabetic patients in the United arab emirates. Rev Diabet Stud. 2009; 6(4): 271-278, doi: 10.1900/RDS.2009.6.271, indexed in Pubmed: 20043039.

9. Al Balushi KA, Al-Haddabi M, Al-Zakwani I, et al. Glycemic control among patients with type 2 diabetes at a primary health care center in Oman. Prim Care Diabetes. 2014; 8(3): 239-243, doi: 10.1016/j.pcd.2014.01.003, indexed in Pubmed: 24472420.

10. Alsulaiman TA, Al-Ajmi HA, Al-Qahtani SM, et al. Control of type 2 diabetes in King Abdulaziz Housing City (Iskan) population, Saudi Arabia. J Family Community Med. 2016; 23(1): 1-5, doi: 10.4103/2230-8229.172221, indexed in Pubmed: 26929722.

11. Yue J, Mao X, Xu K, et al. Prevalence, Awareness, Treatment and Control of Diabetes Mellitus in a Chinese Population. PLoS One. 2016; 11(4): e0153791, doi: 10.1371/journal.pone.0153791, indexed in Pubmed: 27096738.

12. Ding L, Xu Yu, Wang L, et al. 2010 China Non-communicable Disease Surveillance Group. Prevalence and control of diabetes in Chinese adults. JAMA. 2013; 310(9): 948-959, doi: 10.1001/ jama.2013.168118, indexed in Pubmed: 24002281.

13. Ghorbani Be, Yazdanbood A, Amini Sa, et al. Quality of care in 100 diabetic patients in a diabetes clinic in Ardabil. Journal of Ardabil University of Medical Sciences. 2012; 12(3): 239-247. 
14. Mahmood MI, Daud F, Ismail A. Glycaemic control and associated factors among patients with diabetes at public health clinics in Johor, Malaysia. Public Health. 2016; 135: 56-65, doi: 10.1016/j. puhe.2015.07.043, indexed in Pubmed: 26976488.

15. Heidari S, Shirazi F, Sanjari M, et al. Factors influencing glycemic control in type 2 diabetic patients referred to the Institute of Endocrinology and Metabolism, University of Iran Medical Sciences. Iranian Journal of Diabetes and Lipid. 2010; 9(4): 365-375.

16. Amini M, Mehdigoya M, Delavaei $A$, et al. Quality of diabetic management in Iran in 2004-2006. Journal of Medical Council of Islamic Republic of IRAN. 2008: 20-29.

17. Montazem SH, Soleimani A, Hosseini $\mathrm{SH}$, et al. Care quality of patients with diabetes type 2 in the rural areas of Malekan, Iran. Journal of North Khorasan University of Medical Sciences. 2011; 3(3): 75-82, doi: 10.29252/jnkums.3.3.75.

18. Al Mansari A, Obeid $Y$, Islam N, et al. GOAL study: clinical and non-clinical predictive factors for achieving glycemic control in people with type 2 diabetes in real clinical practice. BMJ Open Diabetes Res Care. 2018; 6(1): e000519, doi: 10.1136/bmjdrc-2018-000519, indexed in Pubmed: 30023075.

19. Kassahun T, Eshetie T, Gesesew H. Factors associated with glycemic control among adult patients with type 2 diabetes mellitus: a cross-sectional survey in Ethiopia. BMC Res Notes. 2016; 9: 78, doi: 10.1186/s13104-016-1896-7, indexed in Pubmed: 26861243.

20. Hashemi Nazari S, Bigdelli MA, Khodakarim S, et al. Estimating the effect of direct and indirect factors on glycemic control in type II diabetic patients by path analysis. Iranian Journal of Diabetes and Metabolism. 2018; 2(1), doi: 10.31031/gjem.2018.02.000528.

21. Alramadan MJ, Afroz A, Hussain SM, et al. Patient-related determinants of glycaemic control in people with type 2 diabetes in the gulf cooperation council countries: A Systematic Review. J Diabetes Res. 2018; 2018: 9389265, doi: 10.1155/2018/9389265, indexed in Pubmed: 29682584.

22. Takahashi PY, St Sauver JL, Finney Rutten $\sqcup$, et al. Health outcomes in diabetics measured with Minnesota Community Measurement quality metrics. Diabetes Metab Syndr Obes. 2015; 8: 1-8, doi: 10.2147/DMSO.S71726, indexed in Pubmed: 25565873.
23. Husdal R, Thors Adolfsson E, Leksell J, et al. Associations between quality of work features in primary health care and glycaemic control in people with Type 2 diabetes mellitus: A nationwide survey. Prim Care Diabetes. 2019; 13(2): 176-186, doi: 10.1016/j. pcd.2018.11.005, indexed in Pubmed: 30545793.

24. Iranparvar Alamdari M, Yazdanbood A, Islam Panah S. Quality of care in100diabetic patients in a diabetes clinic in Ardabil. Ardabil J Med Sci. 2012; 12(3): 239-247.

25. Badedi M, Solan Y, Darraj H, et al. Factors Associated with Long-Term Control of Type 2 Diabetes Mellitus. J Diabetes Res. 2016; 2016: 2109542, doi: 10.1155/2016/2109542, indexed in Pubmed: 28090538.

26. Hu H, Hori Ai, Nishiura C, et al. Japan Epidemiology Collaboration on Occupational Health Study Group. Hba1c, Blood Pressure, and Lipid Control in People with Diabetes: Japan Epidemiology Collaboration on Occupational Health Study. PLoS One. 2016; 11(7): e0159071, doi: 10.1371/journal.pone.0159071, indexed in Pubmed: 27437997.

27. Nanayakkara N, Ranasinha S, Gadowski AM, et al. Age-related differences in glycaemic control, cardiovascular disease risk factors and treatment in patients with type 2 diabetes: a crosssectional study from the Australian National Diabetes Audit. BMJ Open. 2018; 8(8): e020677, doi: 10.1136/bmjopen-2017-020677, indexed in Pubmed: 30121593.

28. Care D. Classification and Diagnosis of Diabetes: Standards of Medical Care in Diabetes - 2019. Diabetes Care. 2018; 42(Supplement 1): S13-S28, doi: 10.2337/dc19-s002.

29. Long AN, Dagogo-Jack S. Comorbidities of diabetes and hypertension: mechanisms and approach to target organ protection. J Clin Hypertens (Greenwich). 2011; 13(4): 244-251, doi: 10.1111/j.17517176.2011.00434.x, indexed in Pubmed: 21466619.

30. Nowakowska M, Zghebi SS, Ashcroft DM, et al. The comorbidity burden of type 2 diabetes mellitus: patterns, clusters and predictions from a large English primary care cohort. BMC Med. 2019; 17(1): 145, doi: 10.1186/s12916-019-1373-y, indexed in Pubmed: 31345214. 